\title{
Particulate matter concentration and health risk assessment for a residential building during COVID-19 pandemic in Abha, Saudi Arabia
}

\author{
Salem Algarni ${ }^{1} \cdot$ Roohul Abad Khan $^{2} \cdot$ Nadeem Ahmad Khan $^{3}$ (D) Nabisab Mujawar Mubarak $^{4}$ (D) \\ Received: 26 May 2021 / Accepted: 16 July 2021 / Published online: 28 July 2021 \\ (C) The Author(s), under exclusive licence to Springer-Verlag GmbH Germany, part of Springer Nature 2021
}

\begin{abstract}
Building and its environment are in focus owing to health impact attributed to indoor air quality. This study was carried out to assess indoor air quality in terms of particulate matter (PM) and carbon dioxide in a residential building, during COVD-19 pandemic lockdown from March 25 to April 23, 2020, Abha, Saudi Arabia. The PM concentration range for kitchen, bedroom, and hall were 40,000-81000 $\mu \mathrm{g} / \mathrm{m}^{3}\left(\mathrm{PM}_{0.3}\right), 15,000-26000 \mu \mathrm{g} / \mathrm{m}^{3}\left(\mathrm{PM}_{0.5}\right), 4000-6000 \mu \mathrm{g} / \mathrm{m}^{3}\left(\mathrm{PM}_{1}\right), 1100-1500 \mu \mathrm{g} / \mathrm{m}^{3}$ $\left(\mathrm{PM}_{2.5}\right), 160-247 \mu \mathrm{g} / \mathrm{m}^{3}\left(\mathrm{PM}_{5}\right)$, and 60-95 $\mu \mathrm{g} / \mathrm{m}^{3}\left(\mathrm{PM}_{10}\right)$. The results of this study suggest that bedroom needs to be ventilated as $\mathrm{CO}_{2}$ concentration was reaching $700 \mathrm{ppm}$ during sleep hours. PM concentration was exceeding $300 \mu \mathrm{g} / \mathrm{m}^{3}$ (unhealthy) for all particle sizes of $\mathrm{PM}_{0.3}, \mathrm{PM}_{0.5}, \mathrm{PM}_{1}$, and $\mathrm{PM}_{2.5}$ except for $\mathrm{PM}_{10}$ which was also above safe limits $\left(0-50 \mu \mathrm{g} / \mathrm{m}^{3}\right)$. Also, with influential habit (aromatic smoke), these concentrations increased 2-28 times for PM. The hazard quotient value greater than 1 revealed potential health risk to the inhabitants. Hence, future studies are needed for developing indoor air quality guidelines for residential buildings in Saudi Arabia and better planning and management of energy consumption.
\end{abstract}

Keywords Indoor air quality $\cdot$ COVID-19 $\cdot$ Carbon dioxide $\cdot$ Particulate matter $\cdot$ Hazard quotient

Responsible Editor: Lotfi Aleya

Nadeem Ahmad Khan

er.nadimcivil@gmail.com

Nabisab Mujawar Mubarak

mubarak.mujawar@curtin.edu.my; mubarak.yaseeen@gmail.com

Salem Algarni

saalgarni@kku.edu.sa

Roohul Abad Khan

rakhan@kku.edu.sa

1 Department of Mechanical Engineering, King Khalid University, Abha, Saudi Arabia

2 Department of Civil Engineering, King Khalid University, Abha, Saudi Arabia

3 Department of Civil Engineering, Jamia Millia Islamia, New Delhi, India

4 Department of Chemical and Energy Engineering, Faculty of Engineering and Science, Curtin University, 98009 Miri, Sarawak, Malaysia

\section{Introduction}

The urban population tends to spend more time indoors than outdoors (Huang et al. 2020). Additionally, ongoing COVID19 pandemic has put world population indoors for months. Growing concerns over impact of indoor air quality (IAQ) on human health has led to several studies for various categories of buildings worldwide (Dionova et al. 2020; Huang et al. 2020; Kozielska et al. 2020; Yu et al. 2020). Indoor air quality is directly affected by occupant behaviours and material of the building (especially in extreme climatic conditions). However, in regions with moderate climatic conditions, this effect is reduced. Also, air tightness in buildings with lack of ventilation directly affects IAQ. This relationship is primarily dominant in low-cost housing, contrary to higher income homes, public buildings or multi storeyed buildings with efficient HVAC (Heating, ventilation, and air conditioning) systems, which may reduce or eliminate IAQ dependence on natural ventilation (Fernández-Agüera et al. 2019). IAQ has been studied with respect to various parameters experienced in building environment, viz. carbon dioxide $\mathrm{CO}_{2}$, particulate matter (PM), temperature, humidity, and volatile organic compound (VOCs) (Huang et al. 2004; Yang Razali et al. 2015; Kozielska et al. 2020; Schwela 2020; Yu et al. 2020). 
Primary source of $\mathrm{CO}_{2}$ in indoor environments is human respiration. Also, its increased concentration indicates lesser oxygen concentration. Amoatey et al. (2019) reviewed fate, exposure, and risk to exposed population for emission from oil industries with respect to $\mathrm{SOx}, \mathrm{NO}_{\mathrm{x}}, \mathrm{PM}$, and trace elements. Mokhtar et al. (2014) assess human health risk from emission from coal fired power plants. Khaniabadi et al. (2017) studied impact of air pollution on human health in the urban area of Khorramabad, Iran. However, previous literature has reported health impact for concentrations above $1000 \mu \mathrm{g} / \mathrm{m}^{3}$ (Robertson 2001; Hepple 2005). But, recent literature has revealed health impact at lesser concentrations of $500 \mu \mathrm{g} / \mathrm{m}^{3}$ (Azuma et al. 2018). PM can be classified as coarse inhalable particles $(2.5-10 \mu \mathrm{m})$, fine particles $(<2.5 \mu \mathrm{m})$, and ultrafines $(<0.1 \mu \mathrm{m})$ (Fromme 2019; Bralewska and Rogula-Kozłowska 2020). Also, it was deduced that inhalable particles are only retained in lungs, while other particle sizes were carried out through respiration (Kim et al. 2015). Therefore, $\mathrm{PM}_{2.5}$ and $\mathrm{PM}_{10}$ in majority have been investigated for impact on human health (Bari and Kindzierski 2016; Fromme 2019). However, recent studies have revealed that the finer the particle size, the more impact it will cause on various metabolism in human body (Fig. 1) (Madureira et al. 2020; Deng et al. 2019; Basińska et al. 2019). High concentration of PM is experienced in regions experiencing dust storms such as Saudi Arabia.

In Saudi Arabia, buildings account for $80 \%$ of energy consumption of which $50 \%$ is attributed to residential buildings, which can be understood from the fact that majority of the country experiences arid climatic condition owing to vast deserts spanning across the country. In addition to the building envelope, poor insulation where more than $70 \%$ of the existing building is not insulated contributes significantly to energy consumption. Central HVAC systems in the country are primarily used in public and commercial buildings. However, residential buildings in urban areas across the country are primarily dominated through decentralized air conditioning without mechanical ventilation.

Even though arid climatic conditions are dominant in the country, mountain ranges with an altitude around $2000 \mathrm{~m}$ experience semi-arid moderate climatic conditions especially in the southern region. Irrespective of this, majority of residential old buildings feature small windows attributed to regular dust storm especially during summer season. However, literature on IAQ for Saudi buildings is still lacking. Also, existing literature primarily investigates mechanically ventilated buildings (public and commercial). Additionally, literature on indoor air quality assessment for residential buildings depending primarily on natural ventilation is still lacking not only in Saudi Arabia but also gulf countries, especially when they regularly experience dust storm which is a normal weather pattern experienced in these countries.

This necessitates indoor air quality assessment of residential buildings in Saudi Arabia with decentralized air conditioning or partial mechanical ventilation. Additionally, health risk needs to be assessed. Hence, objectives of this study are as follows: (1) investigate $\mathrm{PM}$ and $\mathrm{CO}_{2}$ concentration during COVID-19 lockdown, (2) determine impact of influential habits (aromatic smoke, smoking, etc.) on indoor air quality, and (3) assess potential health impact from increased concentrations of parameters in concern. Additionally, primary focus in literature for air pollution and health impact is on outdoor air quality and industrial emissions. However, COVID-19 pandemic has presented a scenario which prioritizes impact of indoor air quality on human health. Especially if in the future, the world experiences other similar situations. Also, urban air quality and industrial emissions are restricted to the population who come in contact with it. However, indoor air quality impacts each and every individual

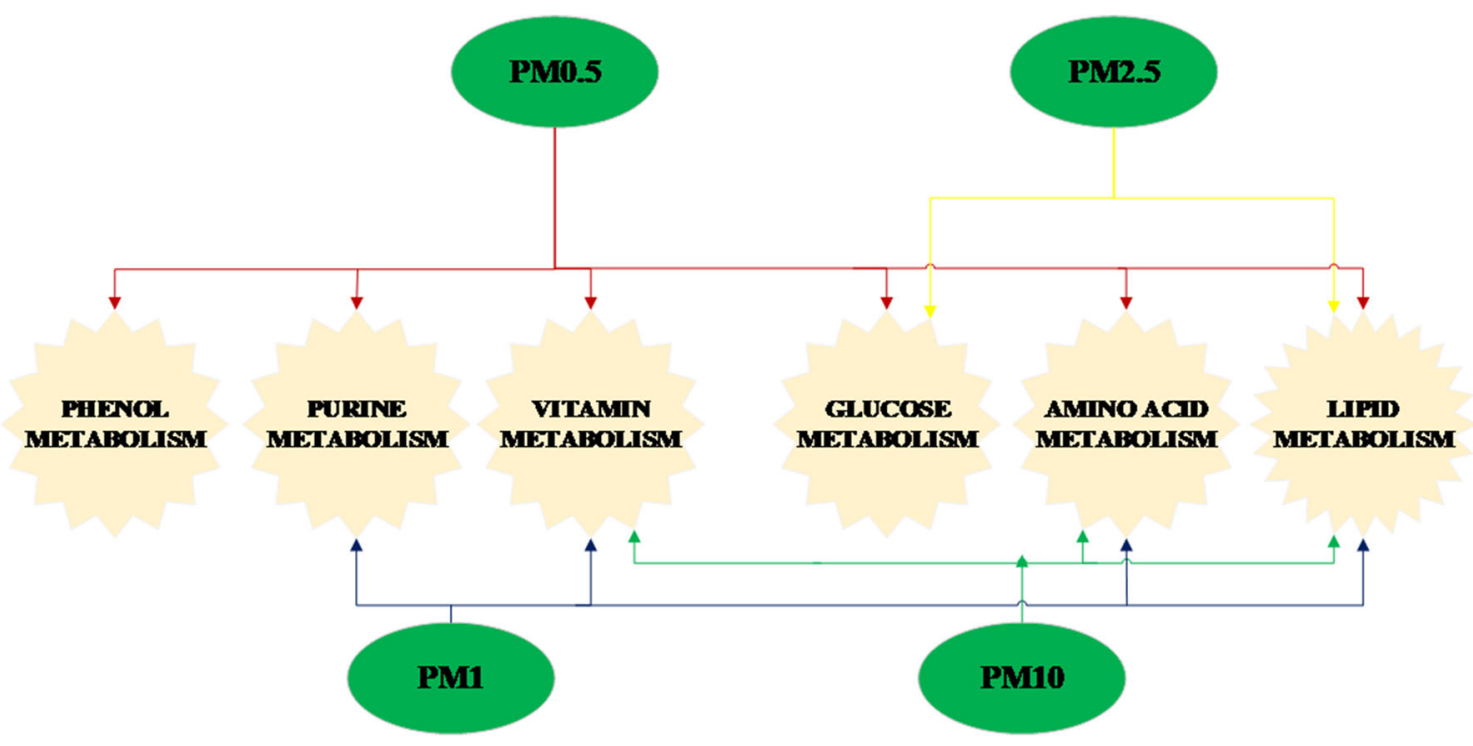

Figure 1 Particulate matter and their identified impact on human metabolism 
on the surface of earth residing in a building. Hence, even if the indoor emission is not high, the exposed population and duration of exposure are much higher.

\section{Methods and data used}

\section{Study area}

The city of Abha is located in the southwest of the Kingdom of Saudi Arabia (18.28N latitude and 42.58E longitude) at $2200 \mathrm{~m}$ above sea level. The city is a prime tourist location in Saudi Arabia. However, with ongoing pandemic of COVID-19, the city underwent lockdown, and population was asked to stay indoors. Nevertheless, it provided an optimum time period for indoor air quality assessment with lesser interference from outdoor environmental conditions (i.e. natural environmental conditions were experienced with less interference of anthropogenic activities owing to ongoing lockdown). Also, this provided a unique opportunity to study influence of influential habits (aromatic smoke, smoking, etc.) on IAQ.

\section{Climatic condition}

Abha experiences semi-arid climatic conditions. Contrary to arid climatic conditions prevailing in majority of Saudi Arabia, Abha enjoys relatively milder weather throughout the year. With December and January reaching minimum temperatures of $11.9^{\circ} \mathrm{C}$ and $12.7^{\circ} \mathrm{C}$, sporadic heating is required especially during nights building. While for summer in month of June and July with temperatures reaching maximum of $25.14^{\circ} \mathrm{C}$, sporadic cooling is required.

\section{Building information}

The building under study is a residential building. The building is located in a residential neighbourhood undergoing construction activities. The building is crossed by several streets, and main approach is a vital main road for the neighbourhood. The building is surrounded by residential buildings on east, west, and south. The residential building is a frame structure with walls made up of hollow cement concrete blocks. Three units in the residence, viz. kitchen $\left(8 \mathrm{~m}^{2}\right)$, bedroom $\left(16 \mathrm{~m}^{2}\right)$, and hall $\left(20 \mathrm{~m}^{2}\right)$, were selected for the study. The residential house was used during the study shown in Fig. 2.

\section{Measurement of $\mathrm{CO}_{2}$ and PM}

The IAQ assessment was conducted in kitchen, bedroom, and hall of the residential house. The measurements were taken during the ongoing pandemic of COVID-19 from March 25 to April 23, 2020. It has to be noted that after this duration of time, the month of Ramadhan came which means the lifestyle of the inhabitants and their timing changes totally with respect to other 11 months of the year. Hence only, 1 month of the study was possible technically. Additionally, Saudi Arabia only experienced 2 months of full and partial lockdown after which it was lifted and no other lockdown has been put in place till date. The instrument was placed at $1 \mathrm{~m}$ height from floor level to record airborne concentrations of $\mathrm{CO}_{2}$ and $\mathrm{PM}$ and avoid readings of depositions concentration especially for PM (Yang Razali et al. 2015). The instrument was placed in each room taking into consideration not to obstruct daily activity and also not to compromise the data quality. Hence, optimized location was identified for each room, and instrument was placed accordingly. Particulate matter $\left(\mathrm{PM}_{0.3}\right.$, $\mathrm{PM}_{0.5}, \mathrm{PM}_{1}, \mathrm{PM}_{2.5}, \mathrm{PM}_{5}$, and $\mathrm{PM}_{10}$ ) and carbon dioxide were measured along with temperature and humidity. In order to determine variation in concentration of parameters in concerned owing to influential habits, readings were taken either with closing natural ventilation or by burning of incense.

\section{Health risk assessment}

Non-carcinogenic risk assessment was calculated to sum up possible adverse impact on health owing to exposure. The risk was estimated based on chronic exposure and acute exposure. Health risks from $\mathrm{PM}_{2.5}$ and $\mathrm{PM}_{10}$ were calculated as per US EPA (US EPA 2009). Non-carcinogenic risk was calculated using Eq. 1

$\mathrm{HQ}=\mathrm{ADI} / \mathrm{RfD}$

where HQ is hazard quotient which is unitless, ADI is average daily inhalation calculated as $\mathrm{mg} / \mathrm{kg}$ body per day weight, and $\mathrm{RfD}$ is reference dose in $\mathrm{mg} / \mathrm{kg}$ body weight per day. $\mathrm{RfD}$ value for $\mathrm{PM}_{2.5}$ was taken as 0.008 .

The chronic exposure was calculated for duration of 1 month, and average daily inhalation $\left(\mathrm{ADI}_{\mathrm{m}}\right)$ was obtained using Eq.2.

$\mathrm{ADIm}=\frac{C X I R X E T X E F X E D}{B W X A T}$

where $C$ is concentration of $\mathrm{PM}_{2.5}$ and $\mathrm{PM}_{10}$, IR is inhalation rate in $\mathrm{m}^{3} \mathrm{~h}^{-1}$, ET is exposure time $\left(\mathrm{h} \mathrm{day}^{-1}\right), \mathrm{EF}$ is exposure frequency (days years ${ }^{-1}$ ), ED is exposure duration (years), BW is body weight $(\mathrm{kg})$, and $\mathrm{AT}$ is average time (years).

Acute exposure from $\mathrm{PM}_{2.5}$ and $\mathrm{PM}_{10}$ was calculated based on average hourly inhalation (AHI) using Eq. 3.

$\mathrm{AHI}=\frac{C X I R}{B W}$

The values of parameters were obtained from US EPA and published literature (US EPA 2009; K. Huang et al. 2020; Di Vaio et al. 2018; Wang et al. 2015; Gruszecka-Kosowska 2018; De Donno et al. 2018). 
Figure 2. Floor plan and front elevation for the study building
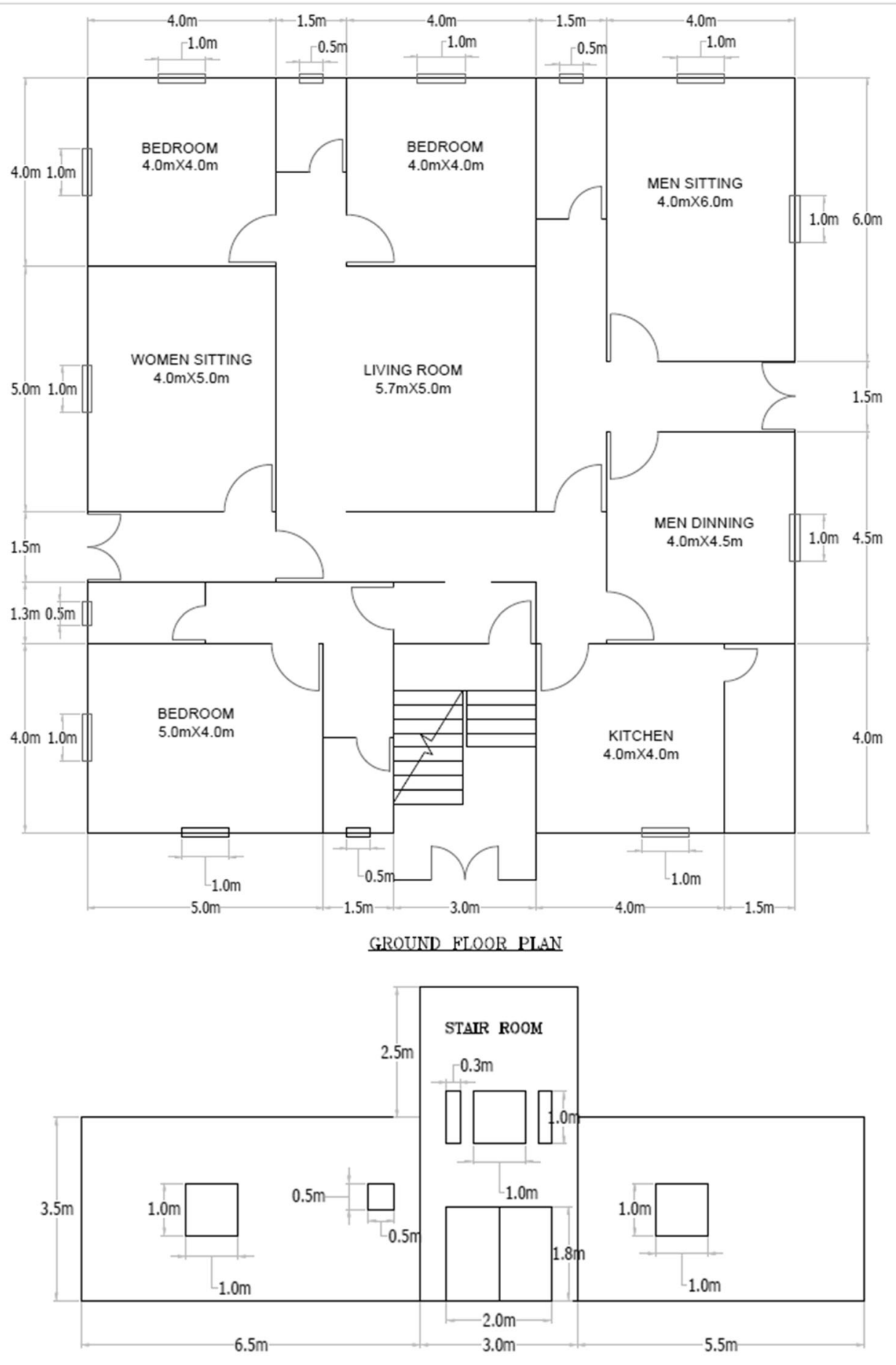

FRONT ELEVATION

\section{Results and discussion}

This study was conducted to evaluate particulate matter and carbon dioxide concentration in residential building in Saudi Arabia, during COVID-19 lockdown, to estimate their potential health risk to the building residents. Three units in the building (kitchen, bedroom, and hall) were investigated using air quality monitors to record the PM and $\mathrm{CO} 2$ concentration. The results are presented for indoor air quality with/without number of occupants present in each unit of house for daily activities. The most probable hours of natural ventilation (NV) have been included in the study based on occupant's 
preference which again was primarily influenced by outdoor temperature (owing to lower temperatures during night and early morning hours). The natural ventilation hours are presented in the study only to present it as a probable solution to address indoor air quality issue.

\section{Carbon dioxide concentration in kitchen, living room, and hall}

Carbon dioxide hourly concentration is presented in Fig. 3 for kitchen, hall, and bedroom. The $\mathrm{CO}_{2}$ concentration fluctuation was significantly affected by number of occupants. Kitchen area experienced minimum $\mathrm{CO}_{2}$ level of $328 \mu \mathrm{g} / \mathrm{m}^{3}$ during night, while in daytime, it reached maximum concentration of $425 \mu \mathrm{g} / \mathrm{m}^{3}$. The bedroom area on other hand experienced lower level of $\mathrm{CO}_{2}$ concentration of $380 \mu \mathrm{g} / \mathrm{m}^{3}$ during daytime, while in night, concentration reached levels of 770 $\mu \mathrm{g} / \mathrm{m}^{3}$. Hall area followed similar pattern of bedroom with $390 \mu \mathrm{g} / \mathrm{m}^{3} \mathrm{CO}_{2}$ concentration during daytime, and in night, it increased to $690 \mu \mathrm{g} / \mathrm{m}^{3}$. However, hourly concentration indicates that $\mathrm{CO}_{2}$ concentration variation is directly dependent on number of occupants. In kitchen area, $\mathrm{CO}_{2}$ concentration increased at breakfast, lunch, and dinner hours. However, for other hours, the concentration was low irrespective of dayor nighttime. Also, similar patterns can be observed for hall and bedroom. However, bedroom concentration reaching 700 $\mu \mathrm{g} / \mathrm{m}^{3}$ for prolonged duration is of concern as sleeping is a basic human necessity and over life time exposure can lead to health implications.

Several studies have accepted $\mathrm{CO}_{2}$ concentration of 1000 $\mu \mathrm{g} / \mathrm{m}^{3}$ as healthy based on the existing guidelines (Griffiths and Eftekhari 2008; Yang Razali et al. 2015; FernándezAgüera et al. 2019). The guidelines were developed based on the health data available which limited the number of studies for health implications at lower concentrations of $\mathrm{CO}_{2}$. Additionally, with natural and mechanical ventilation $\mathrm{CO}_{2}$ concentration can be easily regulated. This again has contributed to lesser focus on considering impact on health from lower concentration of $\mathrm{CO}_{2}$. However, with new studies reporting health implications at those acceptable concentrations as per existing IAQ guidelines puts them as unhealthy concentration (Azuma et al. 2018). Hence, more studies are required to analyse and determine impact of $\mathrm{CO}_{2}$ at lower concentrations.

\section{Impact of influential habits on carbon dioxide concentration}

The influential habits covered in this study are subjected to smoking; it may be due to smoking habit or aromatic smoke. Aromatic smoke is a cultural aspect of Saudi Arabia and exists in their daily activities. From honouring a guest to personal amusement, burning of aromatic wood primarily agarwood is a cultural aspect deeply rooted in the country. Fig. 4 presents carbon dioxide concentration with respect to influential habits for kitchen, bedroom, and hall. The increase in concentration was calculated with respect to minimum carbon dioxide concentration in each unit so as to differentiate between increase with respect to occupants and influential habits with same reference point. In kitchen, an increase of $27 \%, 63 \%$ (bedroom), and $101 \%$ (hall) was attributed to influential habits. The variation in increased concentration can be followed as follows: aromatic smoke was fired and prepared in kitchen where it just stayed for 10-15 min; then with prime combustion conditions, it reached hall; and afterwards when the aromatic wood was past its prime condition, it was transferred to bedroom to create pleasant sleeping and resting environment. The dying combustion conditions in bedroom can also be verified with the fact that carbon dioxide concentration increased to $770 \mu \mathrm{g} / \mathrm{m}^{3}$ which is more than $621 \mu \mathrm{g} / \mathrm{m}^{3}$ as observed from influential habits. However, aromatic smoke is not a regular affair but is in majority restricted to special occasion and major affairs in house. Nevertheless, owing to pandemic succeeding with lockdown forced the occupants
Figure 3. Carbon dioxide hourly concentration with respect to number of occupants (NV natural ventilation, $\mathrm{OK}$ occupants kitchen, $\mathrm{OB}=$ occupants bedroom, $\mathrm{OH}$ occupants hall, $\mathrm{K}=$ kitchen, $\mathrm{B}$ bedroom, $\mathrm{H}$ hall; missing bar means there is no occupancy in either of the three units under study)

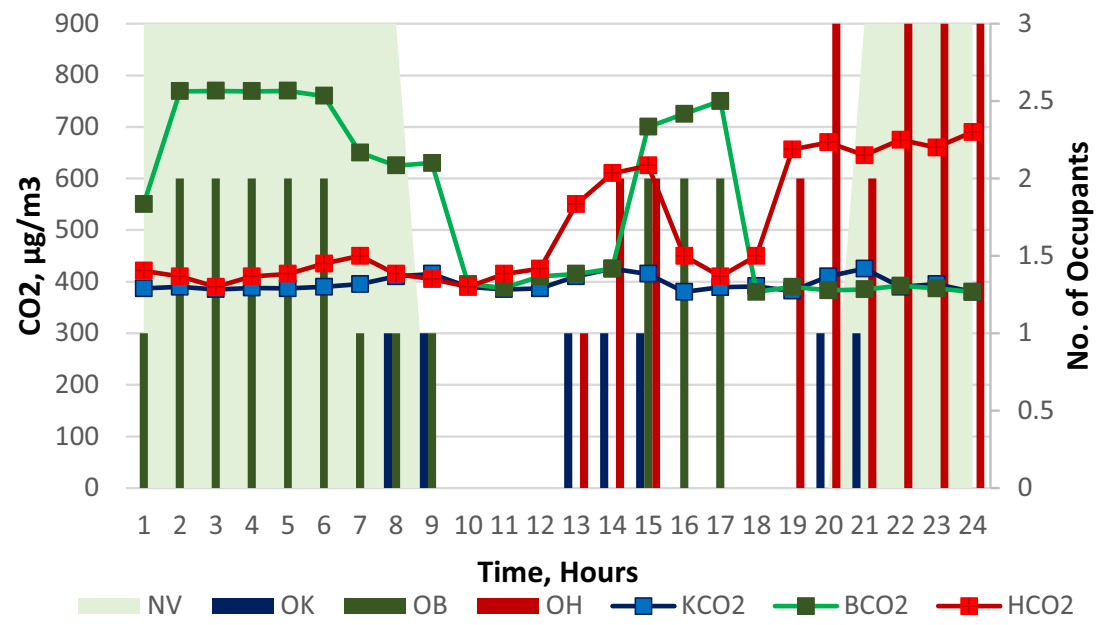


Figure $4 \quad \mathrm{CO}_{2}$ concentration and their health impact zone (HI hall influential habits, $\mathrm{HN}$ hall night, HM hall morning, BI bedroom influential habits, $\mathrm{BN}$ bedroom nights, $\mathrm{BM}$ bedroom morning, $\mathrm{KI}$ kitchen influential habits, $\mathrm{KN}$ kitchen night, KM kitchen morning)

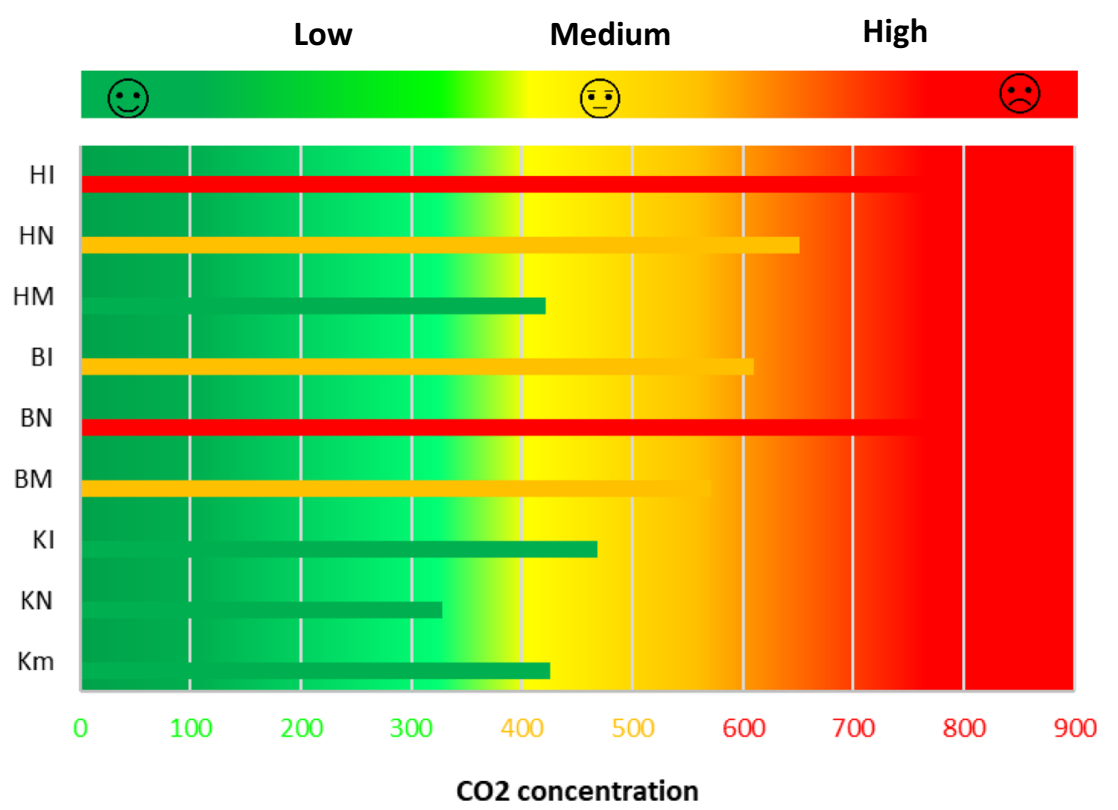

indoors for majority of hours, especially women and children. Hence, occupants adopted and created pleasant atmosphere to ease new restricted indoor lifestyle.

Concentration of $\mathrm{CO}_{2}$ in this study (Fig. 4) was within the permissible threshold limits. However, in bedroom and hall, $\mathrm{CO}_{2}$ concentration was exceeding $600 \mu \mathrm{g} / \mathrm{m}^{3}$ and $700 \mu \mathrm{g} / \mathrm{m}^{3}$, respectively, due to influential habits. $\mathrm{CO}_{2}$ concentration above $500 \mu \mathrm{g} / \mathrm{m} 3$ has been reported to cause increase in heart rate, variation in heart rate, increase in peripheral blood circulation, and blood pressure (Azuma et al. 2018). The exposure over long period of time might result in health issues for the occupants. Irrelevant to hall, the bedroom concentration of $\mathrm{CO}_{2}$ calls for adopting appropriate ventilation method as they are regularly exposed to these concentrations as compared to visitors in hall.

\section{Particulate matter}

This study intends to identify impact of influential habits on IAQ. The IAQ was analysed in terms of particulate matter with respect to number of occupants in each unit (kitchen, bedroom, and hall) covered in this study. The particulate matter concentration for various particle size is present in Fig. 5. The minimum PM concentration ranged between $80\left(\mathrm{PM}_{10}\right)$ $\mu \mathrm{g} / \mathrm{m}^{3}$ and $35640\left(\mathrm{PM}_{0.3}\right) \mu \mathrm{g} / \mathrm{m}^{3}$. The maximum concentration for all particulate matter for kitchen ranged between 120 $\left(\mathrm{PM}_{10}\right) \mu \mathrm{g} / \mathrm{m}^{3}$ and $47380\left(\mathrm{PM}_{0.3}\right) \mu \mathrm{g} / \mathrm{m}^{3}$. For bedroom, minimum range was $39\left(\mathrm{PM}_{10}\right) \mu \mathrm{g} / \mathrm{m}^{3}-29381\left(\mathrm{PM}_{0.3}\right) \mu \mathrm{g} / \mathrm{m}^{3}$, and maximum range was $90\left(\mathrm{PM}_{10}\right) \mu \mathrm{g} / \mathrm{m}^{3}-139786\left(\mathrm{PM}_{0.3}\right) \mu \mathrm{g} /$ $\mathrm{m}^{3}$. The hall area depicted minimum range of $40\left(\mathrm{PM}_{10}\right) \mu \mathrm{g} /$ $\mathrm{m}^{3}-36457\left(\mathrm{PM}_{0.3}\right) \mu \mathrm{g} / \mathrm{m}^{3}$ and maximum range of $115\left(\mathrm{PM}_{10}\right)$ $\mu \mathrm{g} / \mathrm{m}^{3}-43745\left(\mathrm{PM}_{0.3}\right) \mu \mathrm{g} / \mathrm{m}^{3}$. The obtained values of particulate matter are way higher than reported in other studies.
In outdoor conditions, Edmonton (Canada) has reported $\mathrm{PM}_{2.5}$ concentration of $7.11 \mu \mathrm{g} / \mathrm{m}^{3}$ for a study of 6 years duration (Bari and Kindzierski 2016). Also in another study of 26 Chinese cities have reported $\mathrm{PM}_{1}$ concentration of 42.5 $\mu \mathrm{g} / \mathrm{m}^{3}$, and for $\mathrm{PM}_{2.5}$, it was reported as $51.9 \mu \mathrm{g} / \mathrm{m}^{3}$ (Chen et al. 2017). In indoor climate, Changchun (North East China) indoor $\mathrm{PM}_{2.5}$ concentration was observed as $41.59 \mu \mathrm{g} / \mathrm{m}^{3}$ (winter) and $11.15 \mu \mathrm{g} / \mathrm{m}^{3}$ (summer) (Bai et al. 2020). In a study from honking covering 6 residential homes reported $\mathrm{PM}_{10}$ concentration between 100 and $180 \mu \mathrm{g} / \mathrm{m}^{3}$ for living room and 102 and $450 \mu \mathrm{g} / \mathrm{m}^{3}$ for kitchen (Lee et al. 2002). It is evident that the particulate matter concentration observed in this study is way more than reported in literature. Additionally, previous literature with much lower concentration has reported its direct relationship with human health. Hence, it can be deduced that IAQ is of poor quality.

\section{Impact of influential habits on PM concentration}

Particulate matter concentration was already exceeding safe limits. The increase in number of occupants further increased the PM concentration reaching to unhealthy conditions for kitchen, hall, and bedroom. This scenario further worsened with increase in PM concentration attributed to influential habits. Kitchen experienced increase of $79 \%$ for $\mathrm{PM}_{0.3}, 92 \%$ for $\mathrm{PM}_{0.5}, 96 \%$ for $\mathrm{PM}_{1}, 97 \%$ for $\mathrm{PM}_{2.5}, 96 \%$ for $\mathrm{PM}_{5}$, and $92 \%$ for $\mathrm{PM}_{10}$. In bedroom, an increase of $22 \%, 30 \%, 31 \%$, $29 \%, 29 \%$, and $30 \%$ was observed for $\mathrm{PM}_{0.3}, \mathrm{PM}_{0.5}, \mathrm{PM}_{1}$, $\mathrm{PM}_{2.5}, \mathrm{PM}_{5}$, and $\mathrm{PM}_{10}$, respectively. In hall, an increase of $88 \%\left(\mathrm{PM}_{0.3}\right), 92 \%\left(\mathrm{PM}_{0.5}\right), 89 \%\left(\mathrm{PM}_{1}\right), 81 \%\left(\mathrm{PM}_{2.5}\right), 72 \%$ $\left(\mathrm{PM}_{5}\right)$, and $71 \%\left(\mathrm{PM}_{10}\right)$ was observed.

The particulate matter is of concern owing to its deposition in the lungs. Primary mechanisms of deposition are impaction, 

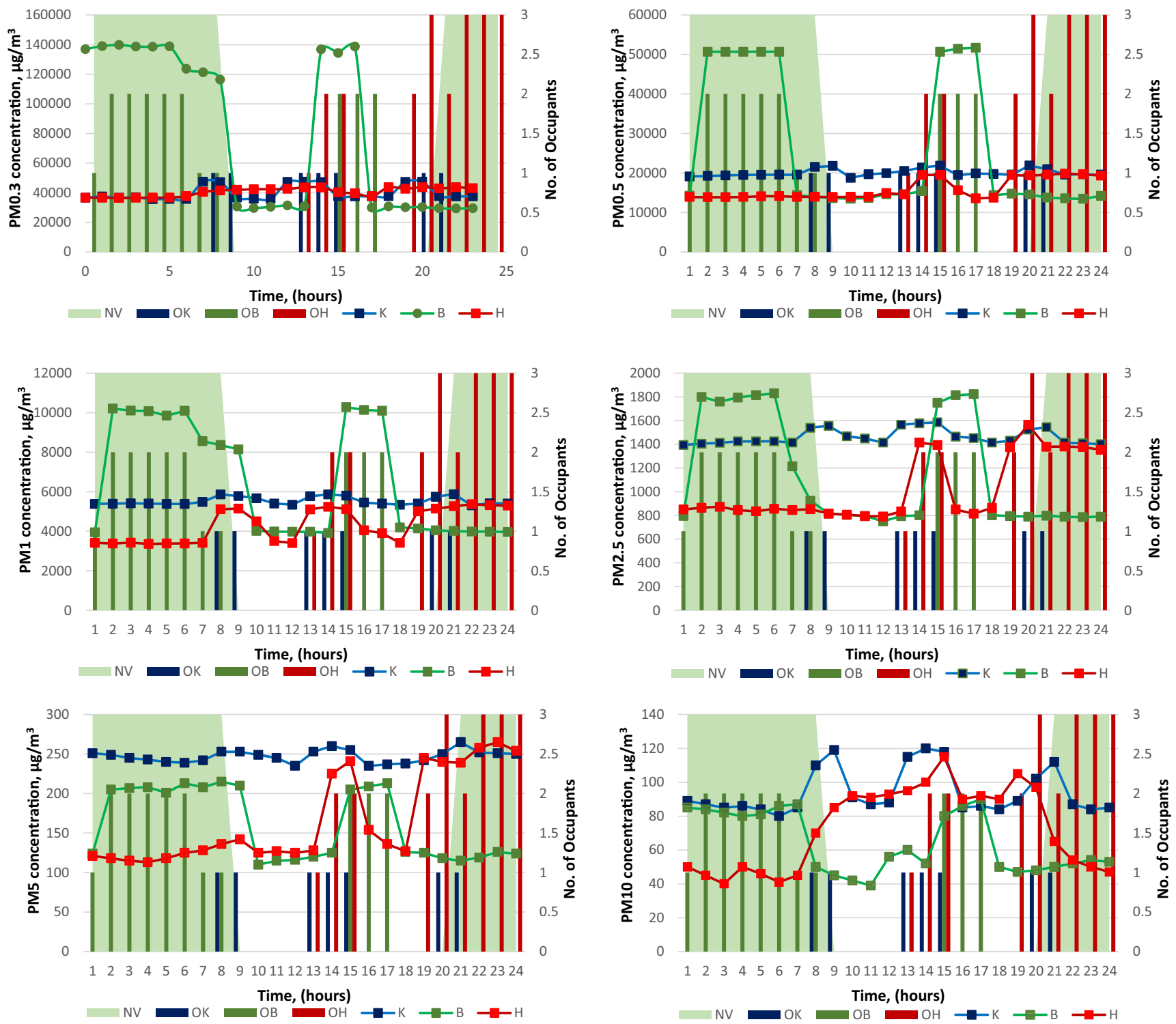

Figure 5. $\mathrm{PM}_{0.3}$ hourly concentration with respect to number of occupants (NV natural ventilation, $\mathrm{OK}$ occupants kitchen, $\mathrm{OB}$ occupants bedroom, $\mathrm{OH}$ occupants hall, $\mathrm{K}$ kitchen, $\mathrm{B}$ bedroom, $\mathrm{H}$ hall)

sedimentation, and diffusion in the lungs through respiratory process. Ultrafine particles deposition in lungs ranging from 95 to $35 \%(0.01-0.1 \mu \mathrm{m})$ is primarily attributed to diffusion. Particulate matter $>0.1-101 \mu \mathrm{m}$ sedimentation and impact are primarily responsible for deposition in lungs. For $0.02-10 \mu \mathrm{m}$ range of particle sedimentation, deposition fraction ranges from 10 to $78 \%$ in lungs, while for impact, the range starts from $2 \mu \mathrm{m}$ with 10\% deposition fraction and reaches up to $90 \%$ for $10 \mu \mathrm{m}$ particle size in lungs. The diffusion mechanism is responsible for $35 \%$ lung deposition at $0.1 \mu \mathrm{m}$ and reduces to $5 \%$ at $0.8 \mu \mathrm{m}$ particle size (Deng et al. 2019). As per air quality index, PM concentration $>300 \mu \mathrm{g} / \mathrm{m}^{3}$ is hazardous. This study observed except of $\mathrm{PM}_{10}$ concentration for all exceeding $300 \mu \mathrm{g} / \mathrm{m}^{3}$ with respect to number of occupants and influential habits. The metabolism affected by PM is presented in Fig 6 .
As per $\mathrm{WHO}, \mathrm{PM}_{2.5}$ acceptable 24-h mean concentration is $25 \mu \mathrm{g} / \mathrm{m}^{3}$, and annual mean concentration is $10 \mu \mathrm{g} / \mathrm{m}^{3}$ while for $\mathrm{PM}_{10} 20 \mu \mathrm{g} / \mathrm{m}^{3}$ and $50 \mu \mathrm{g} / \mathrm{m}^{3}$ for annual mean and 24-h mean concentration, respectively (WHO Regional Office for Europe 1998). The results of this study not only exceed but exceed by many times, the acceptable PM concentration by WHO in absence of natural or mechanical ventilation. Natural ventilation cannot be taken into account especially during COVID-19 owing to early speculations from WHO (airborne transmission of COVID 19) (WHO n.d., March 29, 2020); windows remained shut owing to health concerns. Even if COVID-19 threat was not to be considered, significance of ventilation and importance of IAQ guidelines for Saudi Arabia can be highlighted through this study. For $\mathrm{CO}_{2}$ concentrations reaching 700 ppm especially in bedroom during 
Figure 6 Minimum maximum average and influential habit PM concentration for kitchen, hall, and bedroom (min minimum, max maximum, avg average, $\mathrm{IH}$ influential habit)

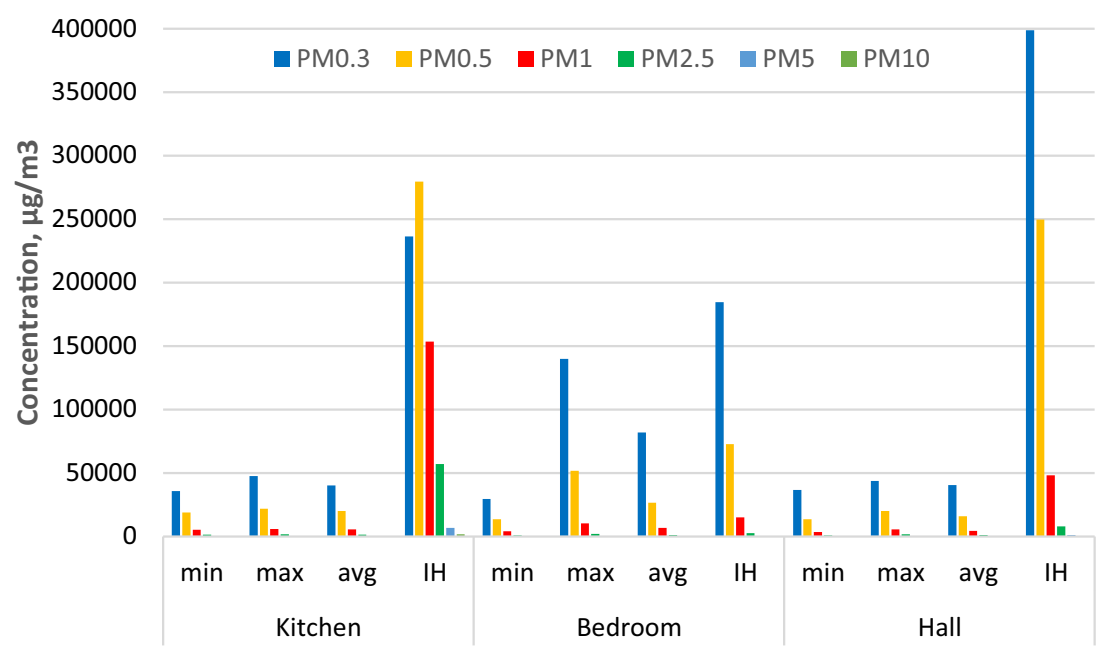

night hour, natural ventilation system is an easy option. However, window size in buildings is a major concern, for kitchen and hall, as population has adopted to smaller window size across the Kingdom owing to regular dust storms. Also, kitchen is an area where homemakers spend most of the time in order to fulfil the nutritional requirement of their respective families. However, in general practice, kitchens are equipped with ventilation fans suitable for bathrooms, which obviously cannot meet the ventilation requirements and puts the homemaker's health at risk. Larger windows or Chimneys needs to be adopted to address this shortcoming.

\section{Health risk assessment}

Hazard risk quotient (HQ) was calculated from average hourly dose and average daily dose as described in "Measurement of CO2 and PM" section. Non-carcinogenic risk sums up all adverse impact on human health except for cancer. HQ value of $<1$ infers no risk from exposure to the pollutant. However, HQ value $>1$ infers potential health risk which is further increased with increase value of HQ. Hence, HQ $>1$ necessitates adoption and implementation of mitigation measures to minimize risk level.

$\mathrm{HQ}_{\mathrm{m}}$ was calculated from $\mathrm{ADI}_{\mathrm{m}}$ for $\mathrm{PM}_{2.5}$ and $\mathrm{PM}_{10}$ for minimum and maximum concentrations. For $\mathrm{PM}_{2.5}$, HQ was $>1$ for all three units. $\mathrm{HQ}$ based on $\mathrm{ADI}_{\mathrm{m}}$ values for kitchen were in between 1.5 and 1.71 and for bedroom $0.8-1.9$, and for hall, the HQ value was $0.8-1.6$ for $\mathrm{PM}_{2.5}$. The $\mathrm{HQ}_{\mathrm{m}}$ value for $\mathrm{PM}_{10}$ was calculated using $\mathrm{ADI}_{\mathrm{m}}$ for kitchen ranged between 0.06 and 0.09 , for bedroom 0.03-0.07, and hall 0.03-0.09. $\mathrm{HQ}_{\mathrm{h}}$ calculated AHI for $\mathrm{PM}_{10}$ was in range of 135-202, 65151, and 67-194 for kitchen, bedroom, and hall, respectively, while for $\mathrm{PM}_{2.5}$, it was in range of 3238-3401, 1741-4248, and 1836-3633 for kitchen, bedroom, and hall, respectively. However, when influential habits are taken into consideration, the trend is similar. However for $\mathrm{HQ}_{\mathrm{m}}$ value for $\mathrm{PM}_{10}$ gives a value of 1.24 which presents potential risk to the inhabitants.

The high values are a serious concern. However, this condition is primarily attributed to the absence of natural ventilation attributed to previous reports suggesting spread of COVID-19 through air. Also, no disease being reported during study period from such high concentrations can be attributed to the fact that Agarwood burning is part and parcel of life in Saudi Arabia. Hence, they are adapted to its exposure and are resistant against high concentration over short period of time. However, if these concentration results from other activities (smoking, barbeque, etc.), it may have adverse impact which needs further investigation to verify.

\section{Conclusion}

This study was carried out to assess IAQ during ongoing pandemic in terms of carbon dioxide and particulate matter concentration. Mean concentration of $\mathrm{CO}_{2}$ was $396 \mu \mathrm{g} / \mathrm{m}^{3}, 551$ $\mu \mathrm{g} / \mathrm{m}^{3}$, and $505 \mu \mathrm{g} / \mathrm{m}^{3}$ for kitchen, bedroom, and hall. Maximum concentration of carbon dioxide was observed in bedroom during sleeping hours reaching up to $770 \mu \mathrm{g} / \mathrm{m}^{3}$. The influential habit (aromatic smoke) added to the concentration of CO2 with observations of $483 \mu \mathrm{g} / \mathrm{m}^{3}, 621 \mu \mathrm{g} / \mathrm{m}^{3}$, and 784 $\mu \mathrm{g} / \mathrm{m}^{3}$ for kitchen, bedroom and hall. Carbon dioxide concentration especially in bedroom, and hall (due to influential habit), may lead to health implications over long-term exposure. For carbon dioxide concentration in bedroom, resorting to natural ventilation will resolve the issue.

The mean concentration for PM in kitchen was observed to be $40012 \mu \mathrm{g} / \mathrm{m}^{3}\left(\mathrm{PM}_{0.3}\right), 20082 \mu \mathrm{g} / \mathrm{m}^{3}\left(\mathrm{PM}_{0.5}\right), 5533 \mu \mathrm{g} / \mathrm{m}^{3}$ $\left(\mathrm{PM}_{1}\right), 1465 \mu \mathrm{g} / \mathrm{m}^{3}\left(\mathrm{PM}_{2.5}\right), 247 \mu \mathrm{g} / \mathrm{m}^{3}\left(\mathrm{PM}_{2.5}\right) \mu \mathrm{g} / \mathrm{m}^{3}$, and $94 \mu \mathrm{g} / \mathrm{m}^{3}\left(\mathrm{PM}_{10}\right)$. In bedroom, it was $81873 \mu \mathrm{g} / \mathrm{m}^{3}\left(\mathrm{PM}_{0.3}\right)$, $26412 \mu \mathrm{g} / \mathrm{m}^{3}\left(\mathrm{PM}_{0.5}\right), 6587 \mu \mathrm{g} / \mathrm{m}^{3}\left(\mathrm{PM}_{1}\right), 1151 \mu \mathrm{g} / \mathrm{m}^{3}$ $\left(\mathrm{PM}_{2.5}\right), 160 \mu \mathrm{g} / \mathrm{m}^{3}\left(\mathrm{PM}_{2.5}\right) \mu \mathrm{g} / \mathrm{m}^{3}$, and $64 \mu \mathrm{g} / \mathrm{m}^{3}\left(\mathrm{PM}_{10}\right)$, and in hall, it was $40542 \mu \mathrm{g} / \mathrm{m}^{3}\left(\mathrm{PM}_{0.3}\right), 15926 \mu \mathrm{g} / \mathrm{m}^{3}$ 
$\left(\mathrm{PM}_{0.5}\right), 5367 \mu \mathrm{g} / \mathrm{m}^{3}\left(\mathrm{PM}_{1}\right), 1565 \mu \mathrm{g} / \mathrm{m}^{3}\left(\mathrm{PM}_{2.5}\right), 166 \mu \mathrm{g} / \mathrm{m}^{3}$ $\left(\mathrm{PM}_{2.5}\right) \mu \mathrm{g} / \mathrm{m}^{3}$, and $62 \mu \mathrm{g} / \mathrm{m}^{3}\left(\mathrm{PM}_{10}\right)$. When influential habit of aromatic smoke was taken into consideration, the PM concentration increased in times with respect to minimum concentration was observed; for kitchen, the increase ranged between 6 and 40 times and for bedroom range was 2-6 times, and for hall, it was 7-14. In terms of PM, the concentration exceeded more than $300 \mu \mathrm{g} / \mathrm{m}^{3}$ putting IAQ under very unhealthy category. The influential habits only worsened the situation. However, in case of PM if not for aromatic smoke, combination of natural and mechanical ventilation needs to be adopted to maintain ambient air quality. Further research work is needed for investigating other indoor air parameters influenced from influential habits, intermittent increased number of occupants, and various seasons of the year and to develop IAQ guideline for Saudi Arabia.

Acknowledgements The authors are thankful to the Institute of Research and Consulting Studies at King Khalid University of supporting this research through grant number \# 37-52-S-2020.

Author contribution Salem Algarni collected data and prepared first draft. Roohul Abad khan data curation and writing - review and editing, and Nadeem Ahmad Khan writing and review and editing, and Nabisab Mujawar Mubarak review and editing

Funding The authors are thankful to the Institute of Research and Consulting Studies at King Khalid University for supporting this research through grant number \# 37-52-S-2020.

Data availability The datasets used and/or analysed during the current study are available from the corresponding author on reasonable request.

\section{Declarations}

Ethical approval and consent to participate This section is "not applicable" for this study as the study does not involve any human participants nor their data or biological material.

Consent for publication This section is "not applicable" for this study as the manuscript did not include any data from individuals.

Competing interests The authors declare no competing interests.

\section{References}

Amoatey P, Omidvarborna H, Baawain MS, Al-Mamun A (2019) Emissions and exposure assessments of SOX, NOX, PM10/2.5 and trace metals from oil industries: a review study (2000-2018). Process Saf Environ Prot 123:215-228. https://doi.org/10.1016/j. psep.2019.01.014

Azuma K, Kagi N, Yanagi U, Osawa H (2018) Effects of low-level inhalation exposure to carbon dioxide in indoor environments: a short review on human health and psychomotor performance. Environ Int 121:51-56. https://doi.org/10.1016/j.envint.2018.08. 059
Bai L, He Z, Li C, Chen Z (2020) Investigation of yearly indoor/outdoor PM2.5 levels in the perspectives of health impacts and air pollution control: case study in Changchun, in the northeast of China. Sustain Cities Soc 53:101871. https://doi.org/10.1016/j.scs.2019.101871

Bari MA, Kindzierski WB (2016) Fine particulate matter (PM2.5) in Edmonton, Canada: source apportionment and potential risk for human health. Environ Pollut 218:219-229. https://doi.org/10.1016/j. envpol.2016.06.014

Basińska M, Michałkiewicz M, Ratajczak K (2019) Impact of physical and microbiological parameters on proper indoor air quality in nursery. Environ Int 132:105098. https://doi.org/10.1016/j.envint.2019. 105098

Bralewska K, Rogula-Kozłowska W (2020) Health exposure of users of indoor sports centers related to the physico-chemical properties of particulate matter. Build Environ 180:106935. https://doi.org/10. 1016/j.buildenv.2020.106935

Chen G, Li S, Zhang Y, Zhang W, Li D, Wei X, He Y, Bell ML, Williams G, Marks GB, Jalaludin B, Abramson MJ, Guo Y (2017) Effects of ambient PM1 air pollution on daily emergency hospital visits in China: an epidemiological study. Lancet Planet Heal 1:e221-e229. https://doi.org/10.1016/S2542-5196(17)30100-6

De Donno A, De Giorgi M, Bagordo F et al (2018) Health risk associated with exposure to PM10 and benzene in three Italian towns. Int J Environ Res Public Health 15:1-13. https://doi.org/10.3390/ ijerph15081672

Deng Q, Deng L, Miao Y, Guo X, Li Y (2019) Particle deposition in the human lung: health implications of particulate matter from different sources. Environ Res 169:237-245. https://doi.org/10.1016/j. envres.2018.11.014

Di Vaio P, Magli E, Caliendo G et al (2018) Heavy metals size distribution in PM10 and environmental-sanitary risk analysis in Acerra (Italy). Atmosphere (Basel) 9. https://doi.org/10.3390/ atmos 9020058

Dionova BW, Mohammed MN, Al-Zubaidi S (2020) Environment indoor air quality assessment using fuzy inference system. Futur Gener Comput Syst Inst Commun Inf Sci 103774:827-848. https://doi.org/10.1016/j.future.2020.02.073

Fernández-Agüera J, Domínguez-Amarillo S, Alonso C, MartínConsuegra F (2019) Thermal comfort and indoor air quality in low-income housing in Spain: the influence of airtightness and occupant behaviour. Energy Build 199:102-114. https://doi.org/10. 1016/j.enbuild.2019.06.052

Fromme H (2019) Particulate matter and ultrafine particles in indoor air, 2nd edn. Elsevier Inc.

Griffiths M, Eftekhari M (2008) Control of CO2 in a naturally ventilated classroom. Energy Build 40:556-560. https://doi.org/10.1016/j. enbuild.2007.04.013

Gruszecka-Kosowska A (2018) Assessment of the Kraków inhabitants' health risk caused by the exposure to inhalation of outdoor air contaminants. Stoch Environ Res Risk Assess 32:485-499. https://doi. org/10.1007/s00477-016-1366-8

Hepple RP (2005) Human health and ecological effects of carbon dioxide exposure. In: Carbon dioxide capture for storage in Deep Geological Formation. pp 1143-1172

Huang YC, Chang CF, Yang SH (2004) Comparison of indoor and outdoor air quality at residential environment in Taiwan by experimeteral monitor. J Aerosol Sci 35:S911-S912. https://doi. org/10.1016/j.jaerosci.2004.06.045

Huang K, Sun W, Feng G, Wang J, Song J (2020) Indoor air quality analysis of 8 mechanically ventilated residential buildings in northeast China based on long-term monitoring. Sustain Cities Soc 54: 101947. https://doi.org/10.1016/j.scs.2019.101947

Khaniabadi YO, Polosa R, Chuturkova RZ, Daryanoosh M, Goudarzi G, Borgini A, Tittarelli A, Basiri H, Armin H, Nourmoradi H, Babaei AA, Naserian P (2017) Human health risk assessment due to ambient PM10 and SO2 by an air quality modeling technique. Process 
Saf Environ Prot 111:346-354. https://doi.org/10.1016/j.psep.2017. 07.018

Kim KH, Kabir E, Kabir S (2015) A review on the human health impact of airborne particulate matter. Environ Int 74:136-143. https://doi. org/10.1016/j.envint.2014.10.005

Kozielska B, Mainka A, Żak M, Kaleta D, Mucha W (2020) Indoor air quality in residential buildings in Upper Silesia, Poland. Build Environ 177:23-26. https://doi.org/10.1016/j.buildenv.2020. 106914

Lee SC, Li WM, Ao CH (2002) Investigation of indoor air quality at residential homes in Hong Kong - case study. Atmos Environ 36: 225-237. https://doi.org/10.1016/S1352-2310(01)00435-6

Madureira J, Slezakova K, Silva AI, Lage B, Mendes A, Aguiar L, Pereira MC, Teixeira JP, Costa C (2020) Assessment of indoor air exposure at residential homes: inhalation dose and lung deposition of PM10, PM2.5 and ultrafine particles among newborn children and their mothers. Sci Total Environ 717:137293. https://doi.org/10.1016/j. scitotenv.2020.137293

Mokhtar MM, Hassim MH, Taib RM (2014) Health risk assessment of emissions from a coal-fired power plant using AERMOD modelling. Process Saf Environ Prot 92:476-485. https://doi.org/10.1016/ j.psep.2014.05.008

Robertson DS (2001) The rise in the atmospheric concentration of carbon dioxide and the effects on human health. Med Hypotheses 56:513518. https://doi.org/10.1054/mehy.2000.1256
Schwela D(D) (2020) Environmental toxicology: air. Wiley-VCH

US EPA (2009) Risk assessment guidance for superfund volume I: human health evaluation manual (Part F, Supplemental Guidance for Inhalation Risk Assessment). Washingotn DC

Wang B, Wang Z, Wei Y et al (2015) Inhalation rates. Highlights Chinese Expo Factors Handb:15-21. https://doi.org/10.1016/b978-0-12803125-4.00012-2

WHO (n.d.) Modes of transmission of virus causing COVID-19: implications for IPC precaution recommendations, scientific brief, WHO

WHO Regional Office for Europe (1998) WHO guidelines for air quality: selected pollutants. Copenhegen, Denmark

Yang Razali NY, Latif MT, Dominick D, Mohamad N, Sulaiman FR, Srithawirat T (2015) Concentration of particulate matter, CO and CO2 in selected schools inMalaysia. Build Environ 87:108-116. https://doi.org/10.1016/j.buildenv.2015.01.015

Yu J, Kang Y, Zhai Z(J) (2020) Advances in research for underground buildings: energy, thermal comfort and indoor air quality. Energy Build 215:109916. https://doi.org/10.1016/j.enbuild.2020.109916

Publisher's note Springer Nature remains neutral with regard to jurisdictional claims in published maps and institutional affiliations. 